\title{
A reform of communication principle for communication engineering specialty in application-oriented universities
}

\author{
Sun Qiaoyun ${ }^{1}$, Zhou Jiang ${ }^{2}$, Wang Min ${ }^{1}$,Zhang Shuguang ${ }^{1}$, Zhang $\mathrm{Yu}^{1}$ \\ ${ }^{1}$ Department of Information, Beijing City University, Beijing, 100083, China \\ ${ }^{2}$ Vehicle Institute, Beijing, 100120, China \\ email: sunqy @bcu.edu.cn
}

\begin{abstract}
Keywords: Communication principle, Applied talent, Course reform
Abstract. The characteristics of communication principle course and the teaching status are analyzed in this paper. Aiming at problems in the teaching process, the reform is performed about the curriculum content, practical teaching and examination mode, etc. Some teaching reform suggestions are put forward for communication principle course in application-oriented universities. The cultivation of the students' practical ability and application ability are strengthened through the course reform. The teaching reform has obtained the good effect and achieved the training aim of applied talents.
\end{abstract}

\section{Introduction}

Communication principle course is one of the most important specialized foundation course of communication engineering specialty. It is an introduction to communication specialized knowledge, and is the core of the specialized courses for the student majoring in communication engineering. This course teaches the composition of communication systems and the technical principles. It pays attention to training students to master basic theory and analysis method of communication systems so as to make the students own good theoretical basis and ability support in the further study and work.

In communication principle course, the concept is abstract, and the requirement of the mathematics knowledge is high. Therefore, the teacher is difficult to teach, and students is difficult to learn this course. The students' mathematical skills, fundamental knowledge, and self-study ability are relatively poor in private colleges. If we adopt cramming teaching mode and emphasize mathematical deduction and theoretical analysis, it is difficult to arouse the enthusiasm of students. Therefore, the teaching reform of communication principle course is needed in order to achieve the training goal of applied talents[1][2]. Communication principle course reform should start from the angle of training students' application ability. The teaching quality and teaching effect should be enhanced constantly by updating the teaching contents, improve teaching methods, optimizing examination mode, etc[3][4].

\section{Integration and Optimization of the Course Content}

Communication principle is a continuity of the course. It is an introductory course to the communication systems and also the foundation of modern communication technology. Its pre-courses are signal and system, theory of probability, high frequency electronic circuit, etc. And its subsequent courses are mobile communication technology, exchange of technology and the communication network, optical fiber communication, etc. In the teaching process, we should communication with the related teaching teachers timely to choose the teaching content reasonably. In this way, we not only can avoid courses teaching content repetition, but also to guarantee the independence and consistency of the relevant specialty courses.

The basic knowledge of communication principle, such as Fourier transform, power spectrum density, correlation function and so on, is the content of signal and system. If the course of communication principle uses the knowledge, the students should review the knowledge by themselves. In the process of teaching, teachers should emphasize understanding and application of the basic knowledge in concrete communication process, without strengthening the basic concept of them. 
Digital modulation technology plays an important part in communication principle course. But due to the limited class hour, only binary digital modulation technique can be analyzed in detail. M-ary digital modulation (such as GMSK and QPSK modulation technology) is not introduced in detail. The relative contents are studied in mobile communications.

Error control coding are studied in information theory. We ignore error control coding content and increase the synchronization technology. synchronization is an important part in communication system. Whether communication system can work effectively or not depends on the synchronization technology to a large extent.

We Should pay attention to integrating theory with practice, and increase application examples to improve the students interest in learning. In analog modulation part, we increased the amplitude modulation and frequency modulation(FM) instance, etc. In digital transmission part, we increase multi-channel digital telephone instance, etc.

\section{Combination of Theoretical Teaching and Practical Teaching}

Experiment teaching is one of the most critical part of the practice teaching. It is not only a useful complement to study, but also a precondition to cultivate the students' practice ability and innovation ability. Communication principle course is very theoretical and practical. Many theories and formulas are abstract. It is difficult to grasp the specific communication process for the students. The practice training can strengthen students' mastery of theoretical concepts and can improve the students' practical ability.

The traditional experiment teaching of communication principle uses the ready-made communication principle experiment box. The experimental box can only carry on the fixed line connection, and give priority to the verification experiment. The experiment projects, especially the comprehensive design experiment projects are limited. It is unfavorable to enhance students' comprehensive application ability and innovation ability. In view of this, the practice teaching of communication principle adopts the combination of hardware and software experiment. We combine traditional experiment box with communication simulation tools. On the one hand, some validation experiments are opened through the traditional experiment box to let the student understand overall communication system and the specific process of communication and signal changes. On the other hand, some comprehensive and design experiments are opened through MATLAB software simulation. With MATLAB software, the performance analysis and system design of communication systems can be carried out easily[5]. For example, if we want to analyze the performance of the digital base-band transmission systems, we can give the bit error rate(BER) and the eye diagram by MATLAB simulation. From the bit error rate curve in Fig. 1, It can be seen that the BER performance of the digital base-band system designed by students is in line with the theoretical values. From Fig. 2, it is can be seen that the eye diagram for in-phase signal is better than the eye diagram for quadrature signal. 


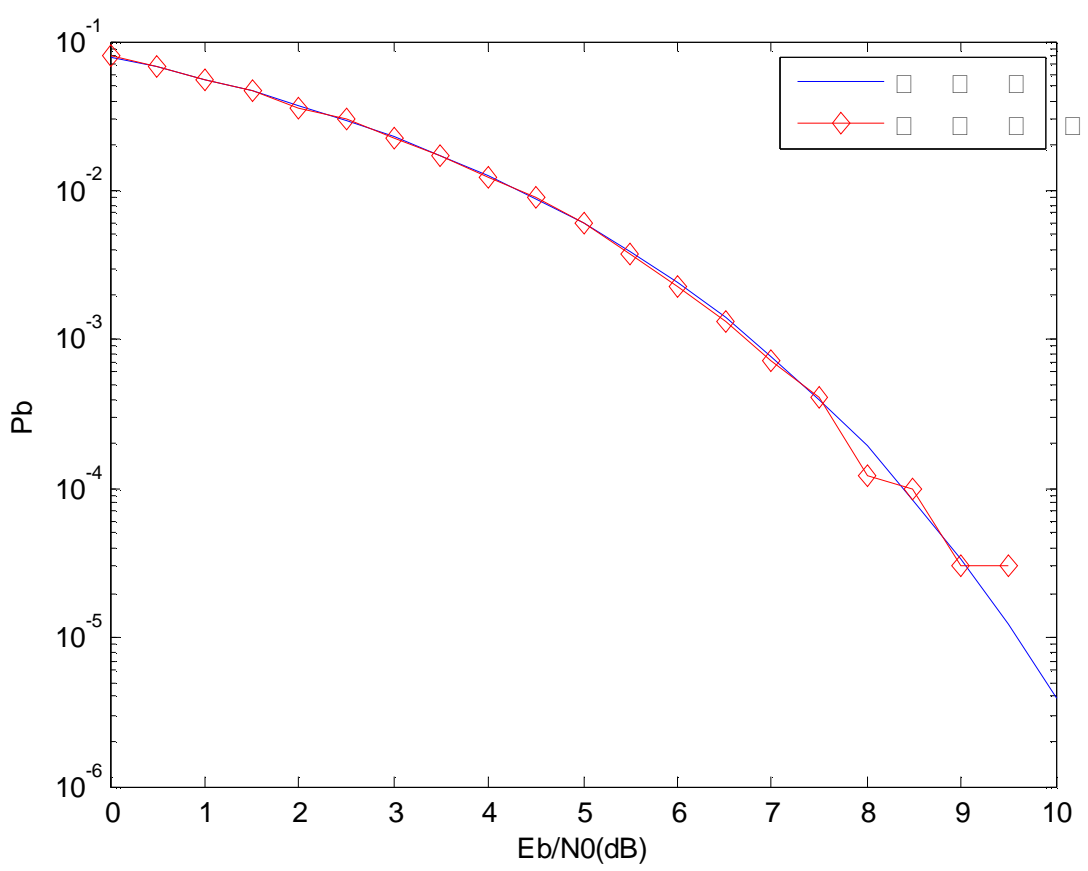

Fig.1 The bit error rate curve of digital base-band system
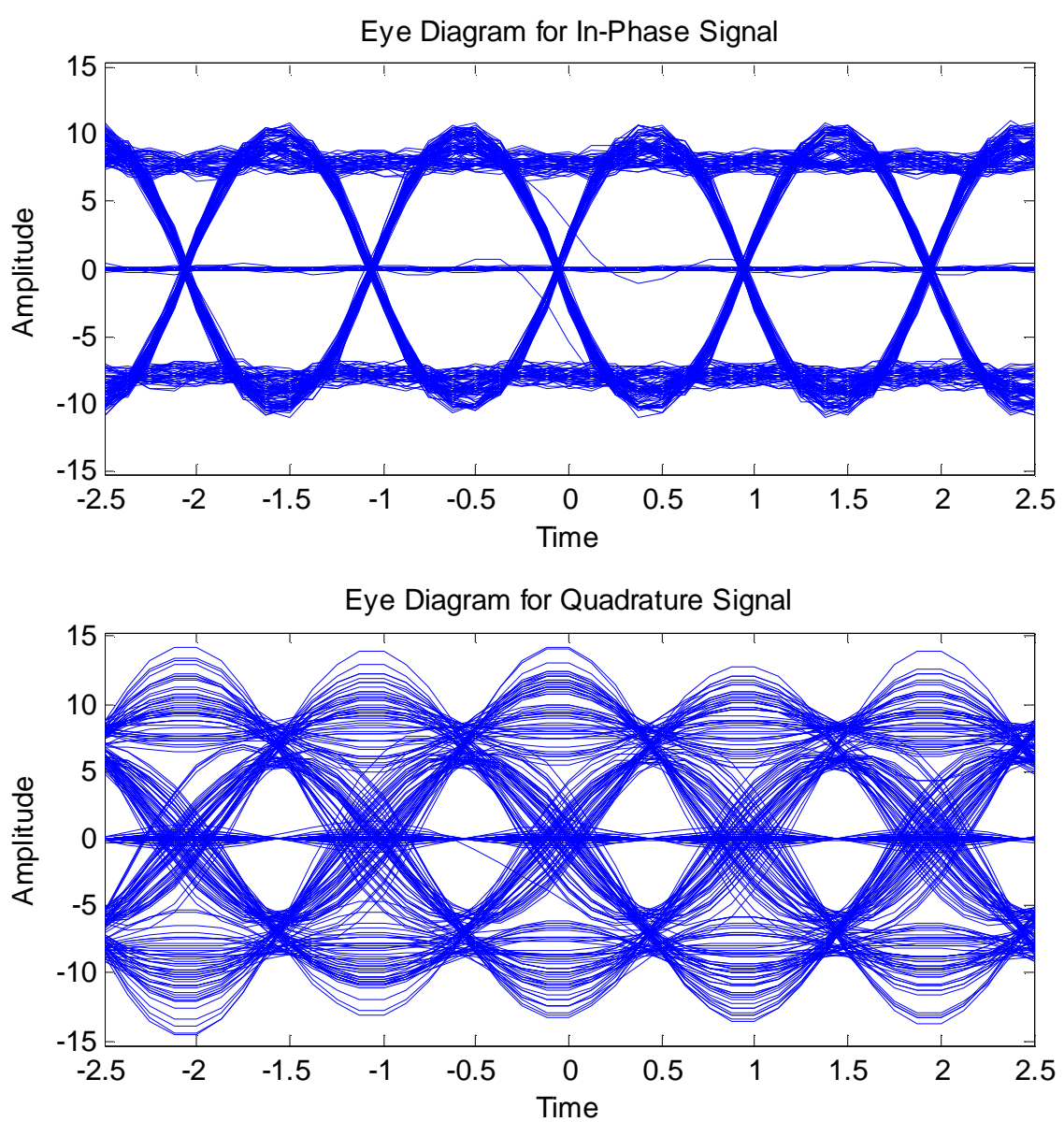

Fig.2 The eye diagram of digital base-band system

\section{Comprehensive Evaluation System}

The current examination form is still the final exam. The traditional examination way focus on examining students' mastery of theoretical knowledge and memory of knowledge. It is not conducive 
to cultivate students' practical operation and technical application ability[6]. For application-oriented colleges and universities, we should highlight the students' ability to solve practical problems and strengthen the process evaluation.

Therefore, It is essential to set up an open, diverse and comprehensive evaluation system to cultivate students' innovative consciousness and practice ability. Comprehensive evaluation system by grades (20 percent), phase examination (30 percent) and the final examination (50 percent).In order to strengthen the process evaluation, the grades include students' attendance, classroom participation, experiment courses, online courses, learning report, etc. Stage examination mainly adopts the form of practice report to improve practical application ability. In practice report evaluation, we mainly pay attention to the assessment of students' ability to solve problems. The teachers should highlight the project practice scores. The final examination adopts the written examination. the written examination should reduce the conceptual problems, increase design and comprehensive subject. The written examination paper increase the open subjective topic on the basis of objective questions. In this way, the students will realize that they must understand and master knowledge to face examination. The students will naturally choose the correct learning attitude.

\section{Summary}

Communication principle is a theoretical and practical course. As far as the problems existing in the traditional teaching are concerned, some reform measures of communication principles course are given from the angle of theoretical teaching and practice teaching. Through the reform on teaching contents, teaching methods and means, examination mode, etc., the teaching quality and teaching effect is significantly improved to achieve the purpose of cultivating applied talents.

\section{Acknowledgements}

This work was financially supported by the Non-Governmental Education Promotion Project of Beijing (Comprehensive practical teaching base for modern communication technology in Beijing City University), the Comprehensive Reform Project of Communication Engineering Specialty (Project No. ZY2014102) and the Course Reform and Practice Project of Communication Principle (Project No. JYC201515).

\section{References}

[1] Zhu Xiangqing, Zeng Hui, Chen Zhixiong. Exploration and Reform of the Communication Theory Teaching Reform[J]. HEILONGJIANG EDUCATION(HIGHER EDUCATIONAL RESEARCH AND EVALUATION), 2011, (1):86-87

[2] Shi Guiming, et al. The research on teaching reform of communication principle course in private universities[J]. China Educational Technique \& Equipment, 2013, (33):111-112

[3] Lu Xiaoli, Cai Xiaoqing, Liu Shuyan. The Application of Diverse Teaching Methods in Communication Principle[J]. Computer Knowledge and Technology, 2013, (20):4663-4664.

[4] Zhu Jun. Teaching Reform on Communication Principle Course on Information Basis[J]. Journal of Hubei Radio \& Television University, 2015, 35(4):30-33

[5] Zeng Jie. Teaching Research of Communication Principle Course Based on Innovative Ability Training[J]. Experiment Science and Technology, 2014, 12(5):95-96+112.

[6] Chen Fangni. Course reform of communication principles for cultivation of application-oriented talents[J]. Journal of Zhejiang University of Science and Technology, 2014, 26(1):68-71 